\section{KEADILAN ORGANISASIONAL DAN KONSEKUENSINYA TERHADAP ORGANIZATIONAL CITIZENSHIP BEHAVIOR GURU SMA DAN SMK KOTA MADIUN*)}

Veronika Agustini Srimulyani ${ }^{1}$; Dyah Kurniawati², Sri Rustiyaningsih ${ }^{3}$

${ }^{1,2}$ Program Studi Manajemen, ${ }^{3}$ Program Studi Akuntansi, FEB, Unika Widya Mandala Madiun

${ }^{1}$ vero@staff.widyamandala.ac.id
JURNAL

MANAJEMEN

INDONESIA

Vol. 17 - No. 2

Agustus 2017

\begin{abstract}
Abstrak
Keadilan organisasional memiliki potensi untuk menciptakan manfaat besar bagi organisasi dan karyawan, dan salah satu manfaatnya adalah menumbuhkan extra-role behavior (ERB) atau organizational citizenship behavior (OCB). Tujuan dari penelitian ini untuk menganalisis konsekuensi keadilan organisasional (keadilan distributif, keadilan prosedural, dan keadilan interaksional) pada organizational citizenship behavior guru SMA dan guru SMK di Kota Madiun. OCB dibagi menjadi dua jenis yaitu citizenship behaviors directed toward individuals (OCB-I) dan citizenship behaviors directed towards the organisation (OCB-O). Penelitian ini menggunakan pendekatan kuantitatif dengan metode survei. Sampel penelitian ini adalah 409 guru, yang dipilih secara non-acak. Data diperoleh dengan menyebarkan kuesioner. Analisis data menggunakan analisis regresi. Hasil penelitian disimpulkan: keadilan distributif dan keadilan interaksional berpengaruh positif signifikan terhadap OCB-I dan OCB-O; keadilan prosedural tidak berpengaruh signifikan terhadap OCB-I tetapi keadilan prosedural berpengaruh positif signifikan terhadap OCB-O.
\end{abstract}

Kata kunci: keadilan distributif, keadilan prosedural, keadilan interaksional, organizational citizenship behavior.

\title{
Abstract
}

Organizational justice has the potential to create substantial benefits for organizations and employees, and one of the benefits is to foster extra-role behavior (ERB) or organizational citizenship behavior (OCB). The purpose of this study was to analyze the consequences in organizational justice be dimensionally (distributive justice, procedural justice, interactional justice) on organizational citizenship behavior high school teachers and vocational teachers in Madiun city. OCB is divided into two types of citizenship behaviors directed toward individuals (OCB-I) and citizenship behaviors directed towards the organization (OCB-O). This study uses a quantitative approach with survey method. The sample was 409 teachers, selected non-random. Data obtained by distributing questionnaires. Analysis of data using regression analysis. The results of this study concluded: distributive justice and interactional justice had significant positive effect on OCB-I and OCB-O; procedural justice does not significantly influence OCB-I but procedural justice had significant positive effect on OCB-O.

Keywords: distributive justice, procedural justice, interactional justice, organizational citizenship behavior.

\section{Pendahuluan}

Salah satu konsep dalam perilaku organisasional yang masih terus mengalami perkembangan hingga saat ini adalah keadilan organisasional (organizational justice) dan dari hasil berbagai kajian dan tinjauan terhadap konsep dan hasil empiris keadilan organisasional menunjukkan bahwa konsep ini memainkan peran yang penting dalam menentukan berbagai sikap dan perilaku individu. Li dan Cropanzano (2009) menyebutkan bahwa keadilan organisasional dapat meningkatkan kinerja individu, melahirkan organizational citizenship behavior (OCB), kesehatan mental yang baik, tingkat stres yang rendah, dan berbagai sikap individu yang baik. Dalam berbagai kajian di berbagai negara, secara konsisten iklim keadilan memiliki peran penting terbentuknya perilaku peran-ekstra (extra-role behavior). Individu yang menampilkan perilaku extra-role yaitu perilaku kerja pegawai yang melebihi tugas pekerjaan sehingga dapat meningkatkan efektifitas dan kinerja organisasi. Dalam kajian penelitian terdahulu ditemukan korelasi positif dan signifikan antara tiga dimensi keadilan 


\section{JURNAL}

MANAJEMEN

INDONESIA

Vol. 17 - No. 2

Agustus 2017 organisasional (keadilan distributif, keadilan prosedural, dan keadilan interaksional) dengan OCB (Jafari dan Bidarian, 2012), sedangkan Polat (2016) menemukan bahwa ketiga dimensi keadilan organisasional tersebut berpengaruh positif signifikan terhadap OCB (Polat, 2016). Penelitian lain oleh Ratnawati dan Khairul Amri (2013) juga menemukan bahwa keadilan organisasional berpengaruh positif signifikan terhadap OCB. Namun pengujian secara empiris oleh para peneliti terdahulu atas pengaruh keadilan organisasional terhadap dua dimensi OCB yaitu citizenship behaviors directed toward individuals (OCB-I) dan citizenship behaviors directed towards the organisation (OCB-O) masih jarang dilakukan.

Menurut Robbin dan Judge (2015), keadilan organisasional adalah persepsi keseluruhan dari apa yang adil di tempat kerja. Ada empat kategori keadilan organisasional yaitu: keadilan distributif, keadilan prosedural, dan keadilan interaksional yang dibedakan menjadi keadilan interpersonal dan keadilan informasional (Colquitt, 2012). Keadilan distributif dapat diartikan sebagai persepsi para pegawai di suatu organisasi yang menganggap bahwa semua yang didapatkannya selama bekerja di organisasi tersebut adalah wajar sesuai imbalan atau kompensasi yang harus diperolehnya. Keadilan prosedural dapat diartikan sebagai persepsi mengenai kebijakan serta prosedur yang digunakan organisasi untuk membuat keputusan telah sesuai dengan semestinya, termasuk kesempatan yang dimiliki pegawai berpartisipasi dalam pembuatan keputusan berkaitan dengan pekerjaan pegawai. Keadilan interaksional dapat diartikan sebagai persepsi tentang kualitas perlakuan antar pribadi di antara para individu yang dirasakan pegawai saat bekerja dengan atasan.

Perilaku OCB adalah sifat alami yang dimiliki pegawai yang merupakan peran ekstra sebagai pelengkap sistem organisasi yang dapat berkontribusi pada efektivitas organisasi (Choi et al., 2014; Elamin dan Tlaiss, 2015). Dengan pengembangan iklim keadilan organisasional diharapkan dapat menumbuhkan OCB di lingkungan kerja, sehingga dapat bermanfaat bagi kelancaran operasional organisasi dan berkontribusi bagi keberhasilan pencapaian tujuan organisasi, terlebih di era yang kompetitif saat ini. Dalam organisasi pendidikan, guru adalah sumber daya manusia suatu organisasi pendidikan dengan peran sentralnya dalam menentukan kualitas output jasa pendidikan yang diberikan. Hal ini disebabkan karena guru adalah pihak yang berinteraksi paling intensif dengan peserta didik, di mana guru banyak berperan memberikan pengaruh terhadap cara berpikir, bersikap dan berperilaku peserta didik. Guru sesuai peran utamanya diharuskan melaksanakan tanggung jawab sebaik-baiknya, terlebih dalam membangun kualitas sekolah, melalui extra-role behavior (ERB) atau OCB yang ditunjukkan guru.

Penelitian ini dilakukan sebagai pengembangan beberapa penelitian terdahulu, seperti Jafari dan Bidarian (2012); Polat (2016) yang mengkaji pengaruh ketiga dimensi keadilan organisasional terhadap OCB; dengan mengkaji kembali dampaknya terhadap dua dimensi OCB yaitu OCB-O dan OCB-I. Ada pun tujuan penelitian adalah: menguji dan menganalisis pengaruh keadilan distributif, keadilan prosedural, dan keadilan interaksional terhadap OCB-O dan OCB-I guru SMA dan SMK Kota Madiun.

\section{Landasan Teori dan Metodologi}

\subsection{Keadilan Organisasional (Organizational Justice)}

Robbins dan Judge (2015) mendefinisikan keadilan organisasional sebagai keseluruhan persepsi mengenai apa yang adil di dalam tempat kerja. Keadilan organisasional dapat menjadi motivator penting di lingkungan pekerjaan, yaitu ketika pegawai merasakan suatu ketidakadilan, moral pegawai akan turun, dan kemungkinan besar pegawai akan meninggalkan pekerjaannya (Cropanzano et al., 2007). Ada tiga dimensi keadilan organisasional yaitu keadilan distributif, keadilan prosedural, dan keadilan interaksional (Aamodt, 2007).

Distributive justice atau keadilan distributif adalah keadilan yang dirasakan, baik jumlah maupun alokasi penghargaan di antara individu dengan memusatkan perhatian pada kewajaran hasil (Robbins dan Judge, 2015), seperti pembayaran yang tepat waktu, jumlah dan manfaatnya (Simpson \& Kaminski, 2007). Keadilan distributif adalah keadilan yang dipersepsikan pegawai dalam hal pertukaran penghargaan finansial (misalnya gaji atau bonus yang diterima) dengan pekerjaan yang dilakukan, dapat mempengaruhi sikap para pegawai terhadap organisasi. 
Procedural justice atau keadilan prosedural adalah keadilan yang dirasakan pada proses yang digunakan untuk menentukan distribusi penghargaan atau menentukan hasil (Robbins dan Judge, 2015); persepsi keadilan dalam prosedur pembuatan keputusan seperti kenaikan gaji, promosi, perubahan pekerjaan, dan umpan balik (Luthans, 2006); sedangkan menurut Coetzee (2005) keadilan prosedural adalah kewajaran atas metode dan prosedur yang digunakan untuk menentukan outcomes. Keadilan prosedural mengacu kepada perasaan adil dari suatu proses pengambilan keputusan yang dibuat, termasuk pemberian kesempatan pegawai dalam proses pengambilan keputusan, menyampaikan ide, atau kepemilikan informasi yang akurat yang digunakan untuk pengambilan keputusan.

Interactional justice atau keadilan interaksional adalah keadilan yang dirasakan pada derajat penerimaan yang salah satunya diperlakukan dengan rasa hormat dan bermartabat; dihubungkan dengan penilaian keadilan berdasarkan kualitas perlakuan interpersonal yang diterima seorang pegawai dengan penuh martabat, perhatian, dan rasa hormat (Bies, 2005). Keadilan interaksional merupakan kombinasi dari kepercayaan bawahan terhadap atasannya dengan keadilan yang nampak dalam lingkungan kerja sehari-hari; lebih bersifat informal jika dibandingkan dengan keadilan prosedural. Keadilan interaksional biasanya mengacu kepada tingkat kejujuran, sensitivitas, dan penghormatan yang ditunjukkan selama interaksi (DeConnick, 2010).

\subsection{Extra-Role Behavior (ERB)}

ERB atau dikenal juga dengan OCB menurut Robbins dan Judge (2015) adalah perilaku pilihan yang tidak menjadi bagian dari kewajiban kerja formal seorang karyawan, namun mendukung berfungsinya organisasi tersebut secara efektif. Menurut Organ et al.,(2006) OCB adalah kebebasan perilaku individu yang secara tidak langsung maupun eksplisit diakui oleh sistem reward, dan memberi kontribusi pada keefektifan dan keefisienan fungsi organisasional. Jadi OCB merupakan perilaku pegawai yang melampaui tugas atau peran formal yang telah ditetapkan organisasi sesuai job description dan dilakukan pegawai dengan sukarela dan tanpa reward formal dari organisasi.

Menurut Organ et al., (2006) dimensi OCB terdiri dari altruism, conscientiousness, sportsmanship, courtesy, dan civic virtue. Dimensi altruism disebut juga peacemaking atau cheerleading yaitu perilaku pegawai dalam memberikan pertolongan meskipun bukan kewajiban yang ditanggungnya, seperti pemberian pertolongan kepada rekan kerja yang mengalami kesulitan baik mengenai tugas organisasional maupun masalah pribadi. Dimensi conscientiousness disebut juga individual initiative adalah perilaku pegawai yang menunjukkan usaha melebihi yang diharapkan organisasi, misalnya efisiensi dalam penggunaan waktu, inisiatif meningkatkan kompetensi, serta secara sukarela mengambil tanggung jawab di luar wewenang atau panggilan tugasnya. Dimensi sportsmanship adalah keinginan untuk menerima (toleransi) atas ketidaknyamanan yang muncul dan kerelaan atau toleransi atas keadaan yang kurang ideal dalam organisasi tanpa mengajukan keberatan atau keluhan sehingga meningkatkan iklim positif di antara anggota organisasi, sopan, dan kooperatif, sehingga dapat menciptakan lingkungan kerja yang lebih menyenangkan. Dimensi courtesy adalah perilaku yang senantiasa menjaga hubungan baik dengan rekan kerja agar terhindar dari masalah-masalah interpersonal melalui perilaku menghargai dan memperhatikan rekan kerja. Dimensi civic virtue yang disebut juga organizational participation merupakan perilaku berkomitmen dari pegawai kepada organisasi secara keseluruhan seperti menghadiri pertemuan, menyampaikan pendapat atau berpartisipasi aktif dalam kegiatan organisasi; terlibat aktif dalam aktivitas organisasi dan peduli atas kelangsungan hidup organisasi (misalnya: mengikuti perubahan dalam organisasi, mengambil inisiatif untuk merekomendasikan bagaimana operasi atau prosedur-prosedur organisasi dapat diperbaiki, dan melindungi sumber daya organisasi).

Pandangan lain tentang dimensi OCB oleh Williams dan Anderson (1991) (Huang \& You (2011) sebagai berikut:

a. Perilaku OCB yang mengarah pada hubungan antara individu dalam organisasi, seperti courtesy dan altruism, disebut citizenship behaviors directed toward individuals 


\section{JURNAL}

MANAJEMEN

INDONESIA

Vol. 17 - No. 2

Agustus 2017

Gambar 1.

Model Penelitian
(OCB-I), yaitu perilaku-perilaku yang memberikan manfaat secara langsung bagi individu lain dan secara tidak langsung memberikan kontribusi pada organisasi, misalnya membantu rekan kerja yang tidak masuk kerja, memberikan perhatian secara personal pada rekan kerja.

b. Perilaku OCB yang menguntungkan organisasi secara keseluruhan meliputi hubungan individu dengan organisasi, seperti conscientiousness, sportsmanship, dan civic virtue, disebut citizenship behaviors directed towards the organisation (OCB-O), yaitu merupakan perilaku-perilaku yang memberikan manfaat bagi organisasi pada umumnya, seperti kehadiran di tempat kerja melebihi norma yang berlaku dan perilaku memelihara ketertiban dengan menaati peraturan-peraturan informal organisasi.

Beberapa hasil penelitian terdahulu membuktikan bahwa keadilan organisasional berperan penting dalam membangun perilaku positif pegawai yang salah satunya adalah OCB. Ratnawati dan Khairul (2013) menyatakan keadilan organisasional berpengaruh signifikan positif terhadap OCB; dan Polat (2016) dan Fory (2014) menemukan bahwa dimensi keadilan distributif, keadilan prosedural, dan keadilan interaksional berpengaruh positif signifikan terhadap OCB. Penelitian lain (Allameh dan Rostami, 2014) menemukan bahwa keadilan prosedural dan keadilan interaksional berpengaruh positif signifikan terhadap OCB-O dan OCB-I, sedangkan pengaruh keadilan distributif terhadap OCB-O dan OCB-I tidak signifikan. Dari hasil penelitian terdahulu mengindikasikan bahwa semakin tinggi persepsi pegawai atas ketiga keadilan organisasional akan berdampak pada semakin tingginya OCB di tempat kerja, baik OCB-I maupun OCB-O.

H1a:Persepsi tentang distributive justice berpengaruh positif dan signifikan terhadap OCB-I

H1b:Persepsi tentang procedural justice berpengaruh positif dan signifikan terhadap OCB-I

H1c:Persepsi tentang interactional justice berpengaruh positif dan signifikan terhadap OCB-I

$\mathrm{H} 2 \mathrm{a}$ :Persepsi tentang distributive justice berpengaruh positif dan signifikan terhadap OCB-O

$\mathrm{H} 2 \mathrm{~b}:$ Persepsi tentang procedural justice berpengaruh positif dan signifikan terhadap OCB-O

$\mathrm{H} 2 \mathrm{c}$ :Persepsi tentang interactional justice berpengaruh positif dan signifikan terhadap OCB-O

H3 :Persepsi tentang organizational juctice berpengaruh positif dan signifikan terhadap OCB

H3

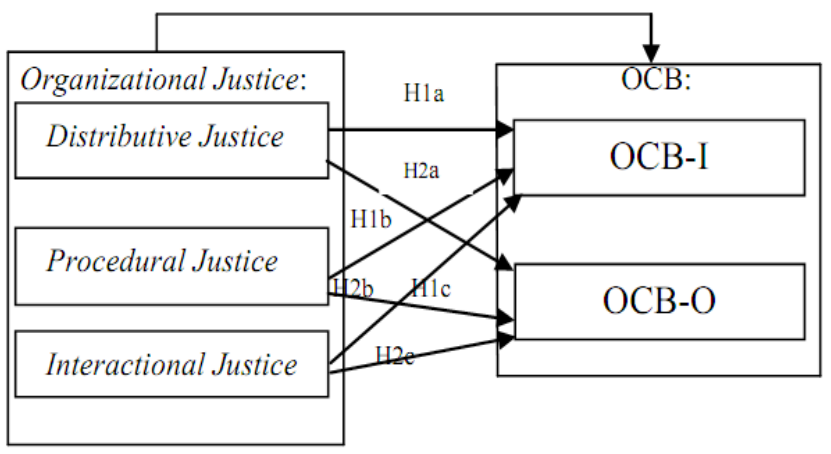

Jenis penelitian ini merupakan penelitian deskriptif verifikatif dan metode penelitian yang digunakan adalah metode explanatory survey. Menurut Sugiyono (2011: 10), explanatory survey merupakan metode penilaian yang bermaksud menjelaskan kedudukan variabel-variabel yang diteliti serta pengaruh antara satu variabel dengan variabel lainnya, dengan mengambil sampel dari suatu populasi serta menggunakan kuesioner sebagai alat pengumpul data utama. Pengambilan data primer dilakukan secara cross sectional study dengan menggunakan kuesioner. Penelitian dilakukan di wilayah Kota Madiun dengan obyek penelitian guru tetap dari SMA dan SMK baik milik negeri maupun swasta di kota Madiun. Metode penentuan sampel menggunakan metode nonprobability sampling yaitu convenience sampling yaitu merupakan metode yang unrestricted yang memungkinkan 
peneliti mengambil elemen populasi dengan mudah. Survei dilakukan dengan menyebarkan kuesioner pada guru tetap SMA dan SMK baik milik negeri maupun swasta di kota Madiun. Analisis pendahuluan yang dilakukan adalah pengujian validitas dan uji reliabilitas data penelitian, serta pengujian asumsi klasik dan analisis komparasi. Untuk pengujian hipotesis dilakukan dengan uji t. Analisis data dilakukan dengan software SPSS.

\begin{tabular}{|c|c|c|c|c|}
\hline Variabel & $\begin{array}{c}\text { Definisi } \\
\text { Operasional }\end{array}$ & Dimensi & $\begin{array}{l}\text { Jumlah } \\
\text { Indikator }\end{array}$ & Literatur \\
\hline Justice & $\begin{array}{l}\text { Persepsi secara } \\
\text { keseluruhan atas } \\
\text { apa yang adil di } \\
\text { lingkungan kerja, } \\
\text { meliputi keadilan } \\
\text { distributif } \\
\text { yaitu keadilan } \\
\text { jumlah imbalan } \\
\text { yang dirasakan } \\
\text { pegawai; keadilan } \\
\text { prosedural } \\
\text { yaitu keadilan } \\
\text { yang dirasakan } \\
\text { pegawai atas } \\
\text { proses yang } \\
\text { digunakan } \\
\text { untuk membuat } \\
\text { keputusan tentang } \\
\text { reward; dan } \\
\text { keadilan } \\
\text { interaksional } \\
\text { yaitu persepsi } \\
\text { pegawai tentang } \\
\text { bagaimana } \\
\text { pegawai } \\
\text { diperlakukan } \\
\text { dengan penuh } \\
\text { martabat, } \\
\text { perhatian, } \\
\text { rasa hormat. }\end{array}$ & $\begin{array}{l}\text { Distributive } \\
\text { Justice } \\
\text { Procedural } \\
\text { Justice } \\
\text { Interactional } \\
\text { Justice }\end{array}$ & $\begin{array}{l}4 \text { indikator } \\
7 \text { indikator } \\
8 \text { indikator } \\
\text { Skala: skala } \\
\text { Likert dari } 1 \\
\text { sampai } 5 \text { poin. }\end{array}$ & $\begin{array}{l}\text { Robbins dan } \\
\text { Judge, (2008), } \\
\text { Allameh dan } \\
\text { Rostami (2014) }\end{array}$ \\
\hline $\begin{array}{l}\text { Citizenship } \\
\text { Behavior } \\
\text { (OCB) }\end{array}$ & $\begin{array}{l}\text { Merupakan } \\
\text { perilaku pegawai } \\
\text { yang melampaui } \\
\text { tugas atau peran } \\
\text { formal yang } \\
\text { ditetapkan job } \\
\text { description } \\
\text { (extra-role) } \\
\text { dan dilakukan } \\
\text { pegawai } \\
\text { dengan sukarela } \\
\text { meskipun tidak } \\
\text { ada reward secara } \\
\text { formal dari } \\
\text { organisasi. }\end{array}$ & $\begin{array}{l}\text { OCB-I: } \\
\text { Altruism } \\
\text { Courtesy } \\
\text { OCB-O: } \\
\text { scientiousness } \\
\text { Sportsmanship } \\
\text { Civic Virtue }\end{array}$ & $\begin{array}{l}3 \text { indikator } \\
3 \text { indikator } \\
3 \text { indikator } \\
3 \text { indikator } \\
3 \text { indikator } \\
\text { Skala: skala } \\
\text { Likert dari } 1 \\
\text { sampai } 5 \text { poin. }\end{array}$ & $\begin{array}{l}\text { Organ et. al, } \\
(2006)\end{array}$ \\
\hline
\end{tabular}

\section{Hasil dan Pembahasan}

Jumlah sekolah swasta di Kota Madiun yang menjadi obyek penelitian berjumlah 40
JURNAL

MANAJEMEN

INDONESIA

Vol. 17 - No. 2

Agustus 2017

Tabel 1.

Pengukuran dan definisi operasional variabel penelitian 


\section{JURNAL}

MANAJEMEN

INDONESIA

Vol. 17 - No. 2

Agustus 2017

Tabel 2.

Profil Responden

Sumber:

Data primer, 2016.

Tabel 3.

Hasil Uji Validitas

Organizational Justice

(OJ) dan OCB

Sumber:

Output SPSS, 2016. (empat puluh) SMA dan SMK di Kota Madiun, dan yang bersedia disurvei sebanyak 30 sekolah yang terdiri dari 9 sekolah negeri dan 21 sekolah swasta. Kuesioner yang disebarkan sebanyak 423 kuesioner bagi guru tetap di 30 SMA dan SMK dengan response rate $96,70 \%$ (sejumlah 409 kuesioner yang kembali).

Profil responden penelitian yang meliputi gender, pendidikan terakhir, dan lama kerja disajikan pada tabel 2.

\begin{tabular}{|c|c|c|}
\hline Keterangan & $\begin{array}{c}\text { Jumlah } \\
\text { (Orang) }\end{array}$ & $\begin{array}{c}\text { Persentase } \\
(\%)\end{array}$ \\
\hline Gender & 184 & 44,98 \\
\hline Laki-laki & 225 & 55,02 \\
\hline Perempuan & 409 & 100 \\
\hline Jumlah & & \\
\hline Tingkat Pendidikan Terakhir & 365 & 89,92 \\
\hline Strata 1 (S1) & 44 & 10,08 \\
\hline Strata $($ S2) & 409 & 100 \\
\hline Jumlah & & 18,58 \\
\hline Lama Kerja & 76 & 17,36 \\
\hline$\leq 5$ tahun & 71 & 38,14 \\
\hline$>5$ tahun s.d. $\leq 10$ tahun & 156 & 21,76 \\
\hline$>10$ tahun s.d. $\leq 20$ tahun & 89 & 4,16 \\
\hline$>20$ tahun s.d. $\leq 30$ tahun & 17 & 100 \\
\hline$>30$ tahun & 409 & \\
\hline Jumlah & & \\
\hline & & \\
\hline
\end{tabular}

Jika dilihat dari jenis kelamin sebanyak 44,98\% responden berjenis kelamin laki-laki dan 55,02\% berjenis kelamin perempuan. Jika dilihat dari tingkat pendidikan sebagian besar responden (89,92\%) memiliki tingkat pendidikan strata 1 (S1) dan sebagian kecil (10,08\%) memiliki tingkat pendidikan strata 2 (S2). Jika dilihat dari masa kerja, sebanyak 18,58\% memiliki masa kerja $\leq 5$ tahun; sebanyak 17,36\% memiliki masa kerja $>5$ tahun s.d. $\leq 10$ tahun; sebanyak 38,14\% memiliki masa kerja $>10$ tahun s.d. $\leq 20$ tahun; sebanyak $21,76 \%$ memiliki masa kerja $>20$ tahun s.d. $\leq 30$ tahun; dan $4,16 \%$ memiliki masa kerja $>30$ tahun.

\begin{tabular}{|c|c|c|c|c|c|}
\hline $\begin{array}{c}\text { Item } \\
\text { Variabel } \\
\text { OJ }\end{array}$ & $\begin{array}{c}\text { Nilai } \\
\mathrm{r}_{\text {hitung }} \text { OJ }\end{array}$ & $\begin{array}{c}\text { Item } \\
\text { Variabel } \\
\text { OCB }\end{array}$ & $\begin{array}{c}\text { Nilai } \\
\mathrm{r}_{\text {hitung }} \text { OCB }\end{array}$ & $\begin{array}{c}\text { Nilai } \mathrm{r}_{\text {tabel }} \\
\alpha=0,025=0,1966\end{array}$ & Keterangan \\
\hline DJ1 & 0,322 & OCBO4 & 0,476 & $\mathrm{r}_{\text {hitung }}>\mathrm{r}_{\text {tabel }}$ & Valid \\
\hline DJ2 & 0,397 & OCBO5 & 0,521 & $\mathrm{r}_{\text {hitung }}>\mathrm{r}_{\text {tabel }}$ & Valid \\
\hline DJ3 & 0,365 & OCBO6 & 0,561 & $\mathrm{r}_{\text {hitung }}>\mathrm{r}_{\text {tabel }}$ & Valid \\
\hline DJ4 & 0,451 & OCBO8 & 0,572 & $\mathrm{r}_{\text {hitung }}>\mathrm{r}_{\text {tabel }}$ & Valid \\
\hline PJ1 & 0,392 & OCBO9 & 0,556 & $\mathrm{r}_{\text {hitung }}>\mathrm{r}_{\text {tabel }}$ & Valid \\
\hline PJ2 & 0,490 & OCBO10 & 0,570 & $\mathrm{r}_{\text {hitung }}>\mathrm{r}_{\text {tabel }}$ & Valid \\
\hline PJ3 & 0,503 & OCBO13 & 0,580 & $\mathrm{r}_{\text {hitung }}>\mathrm{r}_{\text {tabel }}$ & Valid \\
\hline PJ4 & 0,492 & OCBO14 & 0,489 & $\mathrm{r}_{\text {hitung }}>\mathrm{r}_{\text {tabel }}$ & Valid \\
\hline PJ5 & 0,633 & OCBO15 & 0,684 & $\mathrm{r}_{\text {hitung }}>\mathrm{r}_{\text {tabel }}$ & Valid \\
\hline PJ6 & 0,496 & OCBI1 & 0,400 & $\mathrm{r}_{\text {hitung }}>\mathrm{r}_{\text {tabel }}$ & Valid \\
\hline PJ7 & 0,518 & OCBI2 & 0,408 & $\mathrm{r}_{\text {hitung }}>\mathrm{r}_{\text {tabel }}$ & Valid \\
\hline IJ1 & 0,586 & OCBI3 & 0,481 & $\mathrm{r}_{\text {hitung }}>\mathrm{r}_{\text {tabel }}$ & Valid \\
\hline IJ2 & 0,634 & OCBI10 & 0,619 & $\mathrm{r}_{\text {hitung }}>\mathrm{r}_{\text {tabel }}$ & Valid \\
\hline IJ3 & 0,690 & OCBI11 & 0,757 & $\mathrm{r}_{\text {hitung }}>\mathrm{r}_{\text {tabel }}$ & Valid \\
\hline IJ4 & 0,665 & OCBI12 & 0,695 & $\mathrm{r}_{\text {hitung }}>\mathrm{r}_{\text {tabel }}$ & Valid \\
\hline IJ5 & 0,672 & & & $\mathrm{r}_{\text {hitung }}>\mathrm{r}_{\text {tabel }}$ & Valid \\
\hline
\end{tabular}




\begin{tabular}{|c|c|c|c|c|c|}
\hline $\begin{array}{c}\text { Item } \\
\text { Variabel } \\
\text { OJ }\end{array}$ & $\begin{array}{c}\text { Nilai } \\
\mathrm{r}_{\text {hitung }} \text { OJ }\end{array}$ & $\begin{array}{c}\text { Item } \\
\text { Variabel } \\
\text { OCB }\end{array}$ & $\begin{array}{c}\text { Nilai } \\
\mathrm{r}_{\text {hitung }} \text { OCB }\end{array}$ & $\begin{array}{c}\text { Nilai } \mathrm{r}_{\text {tabel }} \\
\alpha=0,025=0,1966\end{array}$ & Keterangan \\
\hline IJ6 & 0,660 & & & $\mathrm{r}_{\text {hitung }}>\mathrm{r}_{\text {tabel }}$ & Valid \\
\hline IJ7 & 0,676 & & & $\mathrm{r}_{\text {hitung }}>\mathrm{r}_{\text {tabel }}$ & Valid \\
\hline IJ8 & 0,608 & & & $\mathrm{r}_{\text {hitung }}>\mathrm{r}_{\text {tabel }}$ & Valid \\
\hline IJ9 & 0,591 & & & $\mathrm{r}_{\text {hitung }}>\mathrm{r}_{\text {tabel }}$ & Valid \\
\hline
\end{tabular}

Pengujian kualitas data dilakukan pada 100 jawaban dari 409 jawaban dan hasilnya memenuhi kriteria validitas dan reliabilitas. Demikian juga untuk pengujian asumsi klasik yang meliputi: uji normalitas data, uji multikolinieritas, uji heteroskedastisitas, dan uji autokorelasi dilakukan atas persamaan regresi yang dikembangkan dan hasilnya memenuhi kriteria asumsi klasik.

\begin{tabular}{|c|c|c|c|}
\hline Variabel & Alpha Hitung & Cronbach Alpha & Keterangan \\
\hline OJ & 0,907 & 0,70 & Sangat Reliabel \\
\hline OCB & 0,891 & 0,70 & Sangat Reliabel \\
\hline
\end{tabular}

Pengukuran dianggap reliable jika hasilnya menunjukkan nilai Cronbach Alpha $>0.7$ (Sekaran, 2003). Pengelompokan tingkat reliabilitas berdasarkan nilai Cronbach Alpha (Budi, 2006: 83) dapat dilihat pada tabel 4b.

\begin{tabular}{|c|c|}
\hline Alpha & $\begin{array}{c}\text { Tingkat } \\
\text { Reliabilitas }\end{array}$ \\
\hline $0,00-0,20$ & Kurang Reliabel \\
\hline$>0,20-0,40$ & Agak Reliabel \\
\hline$>0,40-0,60$ & Cukup Reliabel \\
\hline$>0,60-0,80$ & Reliabel \\
\hline$>0,80-1,000$ & Sangat Reliabel \\
\hline
\end{tabular}

Analisis tambahan berupa uji komparasi dengan tujuan untuk analisis perbandingan keadilan organisasional dan perilaku ekstra-peran (OCB-O dan OCB-I) di sekolah milik negeri dan sekolah milik swasta di Kota Madiun (tabel 5 dan tabel 6).

\begin{tabular}{|l|c|c|c|c|}
\hline \multicolumn{1}{|c|}{ Variabel } & Kepemilikan & $\mathrm{N}$ & Mean & Keterangan \\
\hline \multirow{2}{*}{ Distributive Justice } & 1 & 262 & 3.5 & Tinggi \\
\cline { 2 - 5 } & 2 & 147 & 3.6 & Tinggi \\
\hline \multirow{2}{*}{ Procedural Justice } & 1 & 262 & 3.9 & Tinggi \\
\cline { 2 - 5 } & 2 & 147 & 3.8 & Tinggi \\
\hline \multirow{2}{*}{ Interactional Justice } & 1 & 262 & 3.8 & Tinggi \\
\cline { 2 - 5 } & 2 & 147 & 3.6 & Tinggi \\
\hline \multirow{2}{*}{ OCB-O } & 1 & 262 & 3.9 & Tinggi \\
\cline { 2 - 5 } & 2 & 147 & 3.9 & Tinggi \\
\hline \multirow{2}{*}{$O C B-I$} & 1 & 262 & 3.9 & Tinggi \\
\cline { 2 - 5 } & 2 & 147 & 3.8 & Tinggi \\
\hline \multirow{2}{*}{$O C B$} & 1 & 262 & 4.0 & Tinggi \\
\hline & 2 & 147 & 3.9 & Tinggi \\
\hline
\end{tabular}

Dari tabel 5 dapat dilihat bahwa mean atau rerata kelompok 1 (SMA dan SMK Swasta) dan kelompok 2 (SMA dan SMK Negeri) ada beberapa variabel yang rerata sama dan ada beberapa variabel yang memiliki rerata berbeda. Penafsiran tinggi-rendahnya rerata jawaban responden atas variabel yang diteliti, berdasarkan rentang skala yang digunakan dalam instrumen penelitian yaitu skala 5 point $(5-1=4 / 5=0,8)$, sehingga rentang skala untuk penentuan kriteria sebesar 0.8 . 


\section{JURNAL \\ MANAJEMEN \\ INDONESIA}

Vol. 17 - No. 2

Agustus 2017

Tabel 5b.

Rentang Skala

Tabel 6.

Hasil Pengujian

Compare Means

Independent Sample

T-test

Sumber:

Data primer diolah, 2016.
Dari tabel 5a dapat dilihat bahwa nilai rata-rata persepsi keadilan organisasional oleh para guru dan OCB para guru adalah tinggi. Untuk melihat apakah perbedaan rerata jawaban tersebut signifikan atau tidak, dapat dilihat dari hasil uji levene test dan t-test pada pengujian compare means independent sample T-test (tabel 6).

\begin{tabular}{|c|c|}
\hline Rentang Skala & Kriteria \\
\hline $1.0-1.8$ & Sangat Rendah \\
\hline$>1.8-2.6$ & Rendah \\
\hline$>2.6-3.4$ & Sedang/Moderat \\
\hline$>3.4-4.2$ & Tinggi \\
\hline$>4.2-5.0$ & Sangat Tinggi \\
\hline
\end{tabular}

Praktik keadilan organisasional yang meliputi: keadilan distributif, keadilan prosedural, dan keadilan interaksional di SMA \& SMK swasta dan negeri tidak memiliki perbedaan yang signifikan, hal ini dilihat nilai p-value sebesar $0.055>0.050$ dengan nilai $t$ hitung $1.924<2.000$. Perilaku ekstra-peran para guru SMA/MA \& SMK swasta dan negeri yang memberikan manfaat bagi organisasi (OCB-O) yang meliputi civic virtue, conscientiousness dan sportmanship) tidak memiliki perbedaan yang signifikan, hal ini dilihat nilai p-value sebesar $0.741>0.050$ dengan nilai t hitung $-0.330>-2.000$. Untuk perilaku ekstra-peran para guru SMA \& SMK swasta dan negeri yang secara langsung memberikan manfaat bagi individu lain dan secara tidak langsung juga memberikan kontribusi pada organisasi (OCB-I) yang meliputi: courtessy dan altruism) memiliki perbedaan yang signifikan, hal ini dilihat nilai p-value sebesar $0.008<0.050$ dengan nilai t hitung $2.655>2.000$. Perilaku esktraperan $(\mathrm{OCB})$ secara keseluruhan dari para guru SMA \& SMK swasta dan negeri memiliki perbedaan yang signifikan, hal ini dilihat nilai $p$-value sebesar $0.039<0.050$ dengan nilai $t$ hitung $2.071>2.000$.

\begin{tabular}{|c|c|c|c|c|c|c|c|}
\hline & & \multicolumn{2}{|c|}{$\begin{array}{c}\text { Levene's Test } \\
\text { for Equality of } \\
\text { Variances }\end{array}$} & \multicolumn{4}{|c|}{ t-test for Equality of Means } \\
\hline & & $\mathrm{F}$ & Sig. & $\mathrm{t}$ & df & $\begin{array}{c}\text { Sig. } \\
(2-\text { tailed })\end{array}$ & $\begin{array}{c}\text { Mean } \\
\text { Difference }\end{array}$ \\
\hline \multirow[t]{2}{*}{ DJ } & $\begin{array}{l}\text { Equal } \\
\text { variances } \\
\text { assumed }\end{array}$ & 2.395 & 0.123 & -1.245 & 407 & 0.214 & -0.10808 \\
\hline & $\begin{array}{l}\text { Equal } \\
\text { variances } \\
\text { not assumed }\end{array}$ & & & -1.265 & 316.85 & 0.207 & -0.10808 \\
\hline \multirow[t]{2}{*}{ PJ } & $\begin{array}{l}\text { Equal } \\
\text { variances } \\
\text { assumed }\end{array}$ & 3.652 & 0.057 & 1.222 & 407 & 0.222 & 0.07496 \\
\hline & $\begin{array}{l}\text { Equal } \\
\text { variances } \\
\text { not assumed }\end{array}$ & & & 1.158 & 257.60 & 0.248 & 0.07496 \\
\hline IJ & $\begin{array}{l}\text { Equal } \\
\text { variances } \\
\text { assumed }\end{array}$ & 1.342 & 0.247 & 1.924 & 407 & 0.055 & 0.17558 \\
\hline \multirow[t]{2}{*}{ OCBO } & $\begin{array}{l}\text { Equal } \\
\text { variances } \\
\text { assumed }\end{array}$ & 0.026 & 0.871 & -0.330 & 407 & 0.741 & -0.01859 \\
\hline & $\begin{array}{l}\text { Equal } \\
\text { variances } \\
\text { not assumed }\end{array}$ & & & -0.327 & 293.97 & 0.744 & -0.01859 \\
\hline \multirow[t]{2}{*}{ OCBI } & $\begin{array}{l}\text { Equal } \\
\text { variances } \\
\text { assumed }\end{array}$ & 1.355 & 0.245 & 2.655 & 407 & 0.008 & 0.14022 \\
\hline & $\begin{array}{l}\text { Equal } \\
\text { variances } \\
\text { not assumed }\end{array}$ & & & 2.559 & 270.95 & 0.011 & 0.14022 \\
\hline $\mathrm{OCB}$ & $\begin{array}{l}\text { Equal } \\
\text { variances } \\
\text { assumed }\end{array}$ & 0.191 & 0.663 & 2.071 & 407 & 0.039 & 0.09092 \\
\hline
\end{tabular}




\begin{tabular}{|c|c|c|c|c|c|c|c|}
\hline \multirow{2}{*}{} & & $\begin{array}{c}\text { Levene's Test } \\
\text { for Equality of } \\
\text { Variances }\end{array}$ & \multicolumn{4}{|c|}{ t-test for Equality of Means } \\
\cline { 3 - 8 } & $\mathrm{F}$ & Sig. & $\mathrm{t}$ & $\mathrm{df}$ & $\begin{array}{c}\text { Sig. } \\
\text { (2-tailed) }\end{array}$ & $\begin{array}{c}\text { Mean } \\
\text { Difference }\end{array}$ \\
\hline & $\begin{array}{l}\text { Equal } \\
\text { variances } \\
\text { not assumed }\end{array}$ & & & 2.027 & 283.69 & 0.044 & 0.09092 \\
\hline
\end{tabular}

JURNAL

MANAJEMEN

INDONESIA

Pengujian hipotesis menggunakan uji t yaitu dengan membandingkan antara t hitung dan $\mathrm{t}$ tabel pada taraf signifikansi $5 \%(\alpha=0,05)$ dengan pengujian satu arah. Untuk t tabel dicari dengan menggunakan $\mathrm{df}=\mathrm{n}-\mathrm{k}$, di mana $\mathrm{k}$ merupakan jumlah variabel independen. Nilai-nilai koefisien regresi dan t-hitungnya (CR) diestimasi dari hasil analisis regresi (tabel 7).

\subsection{Pengaruh Keadilan Organisasional terhadap OCB-I}

Berdasarkan tabel 7 besarnya nilai koefisien regresi keadilan distributif(DJ) pada model 1 adalah 0,056 dengan nilai signifikansi sebesar $0,040<$ tingkat $\alpha=0,05$; dan nilai t hitung $1,754>1,649$ ( $\mathrm{t}$ tabel) maka disimpulkan persepsi guru keadilan distributif berpengaruh positif dan signifikan terhadap tingkat OCB-I para guru. Hal ini berarti hipotesis (H1a) "persepsi distributive justice berpengaruh positif dan signifikan terhadap OCB-I", diterima. Temuan ini mengindikasikan bahwa semakin tinggi persepsi para guru atas keadilan yang diterima dalam pemberian reward pada berpengaruh pada semakin baiknya perilaku para guru di tempat kerja seperti: 1)perilaku altruism yaitu kerelaan dalam membantu atau menolong rekan kerja yang mengalami masalah baik terkait tugas-tugas organisasional maupun masalah pribadi; 2)perilaku courtesy yaitu perilaku yang selalu berusaha menjaga hubungan baik melalui perilaku yang menghargai dan memperhatikan rekan kerja agar terhindar dari masalah interpersonal di tempat kerja. Temuan ini menambah mendukung penelitian Polat (2016) yang menemukan bahwa keadilan distributif berpengaruh positif signifikan terhadap OCB.

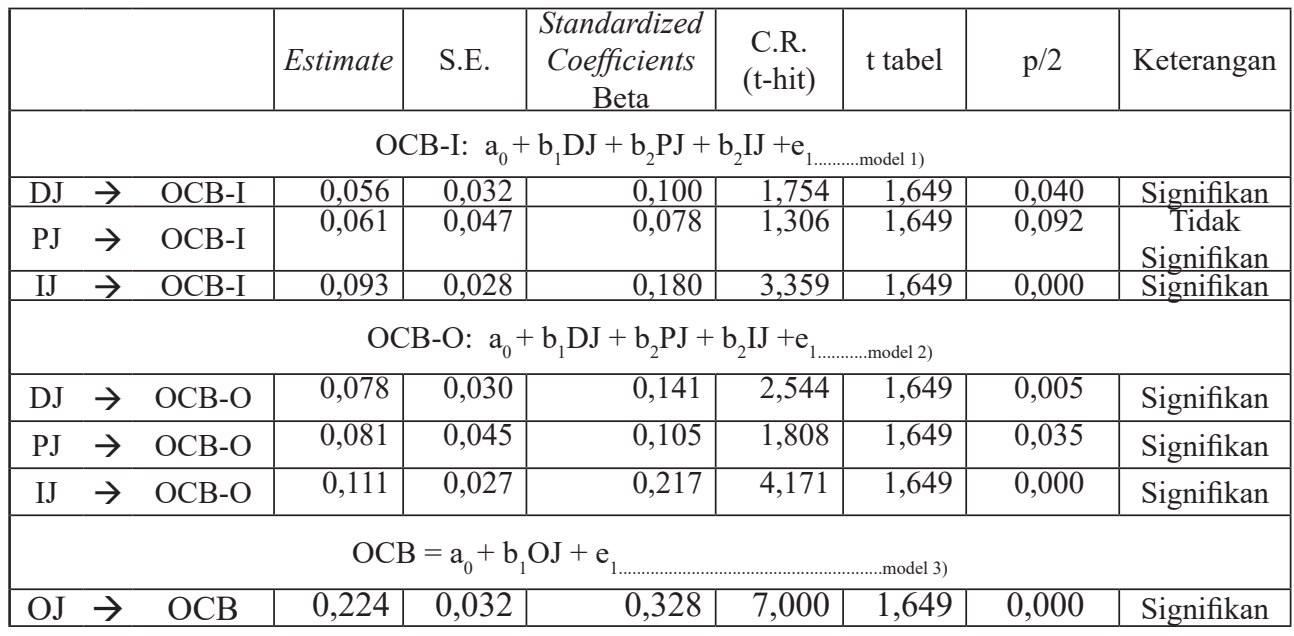

Besarnya nilai koefisien regresi keadilan prosedural (PJ) pada model 1 sebesar 0,061 dengan $\mathrm{p}$ value $0,092>0,05(\alpha)$ serta nilai t hitung sebesar $1,306<1,649$ hal ini berarti persepsi guru atas keadilan prosedural tidak berpengaruh signifikan terhadap OCB-I, namun arahnya positif, sehingga hipotesis (H1b) "persepsi procedural justice berpengaruh positif dan signifikan terhadap OCB-I", ditolak. Hasil ini mengindikasikan bahwa persepsi para guru atas keadilan prosedural dalam pembuatan keputusan kompensasi, promosi, variasi pekerjaan serta umpan balik tidak berdampak signifikan pada pembentukan perilaku altruism dan courtesy para guru. Veronika (2009) menemukan bahwa keadilan prosedural merupakan salah satu anteseden dari komitmen organisasional, sementara Mahmudah (2010) menemukan bahwa keadilan organisasional berdampak tidak langsung pada OCB melalui komitmen pegawai dan kepuasan kerja sebagai mediator. Hal ini mengindikasikan bahwa keadilan prosedural yang dipersepsikan para guru tidak berdampak langsung bagi pembentukan OCB-I para guru, melainkan didahului dengan terbentuknya kepuasan kerja

Vol. 17 - No. 2

Agustus 2017

Tabel 7.

Ringkasan Hasil Analisis Regresi Linier

Sumber:

Output SPSS, 2016. 


\section{JURNAL}

MANAJEMEN INDONESIA

Vol. 17 - No. 2

Agustus 2017 dan komitmen organisasional para guru. Hasil ini tidak mendukung Allameh dan Rostami (2014) tentang temuannya bahwa ada pengaruh langsung procedural justice secara positif dan signifikan terhadap OCB-I.

Pada tabel 7 nilai koefisien regresi keadilan interaksional (IJ) pada model 1 sebesar 0,093 dengan taraf signifikan 5\%, nilai t hitung sebesar 3,359>1,649 dan nilai signifikansi sebesar $0,000<$ tingkat $\alpha=0,05$ hal ini berarti bahwa persepsi para guru tentang keadilan interaksional di tempat kerja berpengaruh positif dan signifikan terhadap OCB-I, sehingga hipotesis (H1c) "persepsi interactional justice berpengaruh positif dan signifikan terhadap OCB-I", diterima. Temuan dari penelitian ini mengindikasikan bahwa semakin tinggi persepsi para guru tentang keadilan interaksional (perlakuan yang penuh martabat, perhatian, dan rasa hormat yang diterima para guru), dapat menumbuhkan semakin tingginya OCB-I (perilaku altruism dan perilaku courtesy). Hasil ini mendukung temuan Allameh dan Rostami (2014) tentang pengaruh positif dan signifikan dari keadilan interaksional terhadap OCB-I.

\subsection{Pengaruh Keadilan Organisasional terhadap OCB-O}

Berdasarkan tabel 7 nilai koefisien regresi distributive justice (DJ) pada model 2 adalah 0,078 dengan nilai signifikansi sebesar $0,005<$ tingkat $\alpha=0,05$ dan nilai t hitung sebesar 2,544>1,649; hal ini berarti persepsi para guru atas distributive justice di tempat kerja berdampak positif dan signifikan terhadap tingkat OCB-O para guru. Hal ini berarti hipotesis (H2a) "persepsi distributive justice berpengaruh positif dan signifikan terhadap OCB-O", diterima. Hasil ini mendukung Polat (2016) dan Fory (2014) bahwa distributive justice berpengaruh positif dan signifikan terhadap OCB. Hasil ini mengindikasikan bahwa semakin tinggi persepsi para guru atas keadilan yang diterima dalam pemberian imbalan dapat menumbuhkan semakin tingginya perilaku para guru berkaitan dengan perilaku-perilaku yang menguntungkan organisasi secara keseluruhan, seperti: conscientiousness, sportsmanship, dan civic virtue. Sesuai the big five theory, bahwa perilaku conscientiousness adalah sikap yang lebih berhati-hati dan mendengarkan kata hati, memiliki kontrol diri yang bagus, terorganisir, memprioritaskan tugas, mengikuti norma dan peraturan, dan lain sebagainya. Contoh perilaku conscientiousness yang ditunjukkan para guru adalah tingkat penerimaan dan tingkat kepatuhan guru pada aturan dan prosedur yang ada di dalam organisasi. Perilaku sportsmanship dapat dilihat dari tingkat toleransi dan keluhan (complaint) individu dalam pekerjaannya. Para guru yang mempunyai tingkat sportsmanship tinggi sangat memperhatikan hal-hal detail dalam pekerjaannya, berperilaku fair dalam menjalankan pekerjaan dengan tingkat keluhan yang minimum serta diikuti kemampuan adaptasi yang tinggi dengan situasi dan lingkungan kerjanya. Perilaku civic virtue seseorang dapat ditunjukkan melalui perilaku turut serta secara penuh (self involvement) dan perhatian lebih pada organisasi tempatnya bekerja. Perilaku civic virtue yang tinggi para guru ditunjukkan pada tingginya perhatian para guru pada kepentingan organisasi tempat kerja dengan berperan aktif dalam semua kegiatan yang ada dalam organisasi, seperti: training pegawai, workshop, kepanitiaan dan lain-lain serta tingkat perhatian para guru atas informasi penting yang dapat bermanfaat bagi sekolah.

Pada tabel 7 dapat dilihat nilai koefisien regresi keadilan prosedural (PJ) pada model 2 sebesar 0,081 dengan nilai signifikansi sebesar $0,035<$ tingkat $\alpha=0,05$ dan nilai t hitung sebesar 1,808>1,649 (t tabel) sehingga disimpulkan bahwa persepsi guru atas keadilan organisasional di tempat kerja berpengaruh positif dan signifikan terhadap OCB-O guru. Dengan demikian hipotesis (H2b) " persepsi procedural justice berpengaruh positif dan signifikan terhadap OCB-O”, diterima. Hasil ini mengindikasikan bahwa persepsi atas keadilan yang dirasakan para guru atas proses yang digunakan untuk pembuatan keputusan berdampak kuat pada pembentukan perilaku OCB-O para guru. Temuan ini mendukung Allameh dan Rostami (2014) bahwa keadilan prosedural berpengaruh positif dan signifikan terhadap OCB-O.

Nilai koefisien regresi keadilan interaksional (IJ) pada model 2 sebesar 0,111 dengan nilai signifikansi sebesar $0,000<$ tingkat $\alpha=0,05$ dan nilai t hitung 4,171>1,649 (t tabel) sehingga disimpulkan bahwa persepsi keadilan interaksional para guru berpengaruh secara positif dan signifikan terhadap OCB-O para guru. Hal ini berarti hipotesis $(\mathrm{H} 2 \mathrm{c})$ "persepsi interactional justice berpengaruh positif signifikan terhadap OCB-O”, diterima. Hasil penelitian mengindikasikan bahwa semakin tinggi persepsi para guru keadilan interaksional di tempat kerja, dapat menumbuhkan semakin tingginya OCB-O para guru. 
Hasil ini mendukung penelitian Allameh dan Rostami (2014) menemukan bahwa keadilan interaksional berpengaruh positif dan signifikan terhadap OCB-O.

\subsection{Pengaruh Keadilan Organisasional terhadap OCB}

Pada tabel 7 dapat dilihat besarnya nilai koefisien regresi keadilan organisasional (OJ) pada model 3 sebesar 0,224 dengan nilai signifikansi sebesar $0,000<$ tingkat $\alpha=0,05$ dan t hitung sebesar 7,000>1,649 (t tabel) sehingga disimpulkan bahwa persepsi para guru secara keseluruhan atas keadilan organisasional berpengaruh positif dan signifikan terhadap OCB para guru. Artinya hipotesis (H3) yang menyatakan: persepsi keadilan organisasional berpengaruh positif dan signifikan terhadap OCB, diterima.

Pengaruh keadilan organisasional terhadap OCB juga berlaku dalam konteks organisasi pendidikan. Apabila guru diperlakukan secara adil oleh pihak sekolah atau pimpinan sebagai pemegang otoritas sekolah, maka hal itu akan dinilai positif para guru sehingga para guru rela melakukan tindakan OCB-I dan OCB-O. Penilaian guru tentang sejauh mana para guru diperlakukan secara adil oleh organisasi dalam bentuk keadilan distributif, keadilan prosedural, dan keadilan interaksional dapat mendorong para guru rela melakukan sesuatu di luar peran utamanya sebagai guru, agar sekolah tempat bekerja dapat berkembang, tanpa berpikir tentang penghargaan. Dalam hal ini OCB para guru yang merefleksikan tindakan para guru karena kesukarelaan di luar perannya (altruism, courtesy, conscientiousness, sportsmanship, dan civic virtue) pada gilirannya dapat memberikan kontribusi positif bagi perkembangan dan efektivitas organisasi serta dapat berdampak pada kualitas kehidupan kerja para guru itu sendiri. Hasil penelitian mendukung studi empiris sebelumnya (Polat, 2016 dan Fory, 2014) yang menemukan bahwa keadilan organisasional berdampak positif signifikan terhadap pembentukan OCB. Dengan demikian, penelitian ini semakin menguatkan fakta empiris bahwa persepsi keadilan organisasional anggota organisasi mempengaruhi secara positif dan signifikan organizational citizenship behavior anggota organisasi.

\section{Kesimpulan, Keterbatasan Penelitian dan Saran}

Hal-hal yang dapat disimpulkan atas hasil penelitian adalah bahwa keadilan organisasional secara overall berdampak positif dan signifikan terhadap tingkat OCB anggota organisasi. Secara dimensional, praktik keadilan organisasional yang terdiri dari keadilan distributive, keadilan prosedural dan keadilan interaksional dapat menumbuhkan OCB-O, sedangkan dampak keadilan organisasional secara dimensional tersebut adalah ada satu dimensi yaitu keadilan prosedural tidak berpengaruh signifikan terhadap OCB-I sementara keadilan distributif dan keadilan interaksional berpengaruh positif dan signifikan terhadap OCB-I. Namun demikian, dapat disimpulkan bahwa persepsi keadilan di tempat kerja dapat membantu menjelaskan mengapa anggota organisasi melakukan OCB. Persepsi keadilan anggota organisasi juga penting untuk tetap diperhatikan karena selain dapat mempengaruhi sikap OCB juga berdampak pada kinerja secara positif (Veronika dkk., 2015) dan juga mempengaruhi perlakuan adil anggota organisasi pada peningkatan kualitas pelayanan terhadap orang lain, efektifitas kelompok dan organisasi.

Dalam penelitian ini terdapat kekurangan dan keterbatasan yaitu:

1. Metode pengumpulan data dalam penelitian ini dilakukan hanya dengan metode survei melalui kuesioner, peneliti tidak melakukan wawancara atau terlibat secara langsung dalam aktivitas, sehingga kesimpulan yang diambil hanya berdasarkan pada data yang dikumpulkan melalui penggunaan kuesioner.

2. Software SPSS tidak praktis jika digunakan untuk pengujian pengaruh langsung dan tidak langsung.

Berdasarkan kesimpulan dan keterbatasan yang telah diuraikan, maka diberikan saransaran sebagai berikut:

1. Untuk penelitian keadilan organisasional selanjutnya, dapat dikembangkan menjadi 4 dimensi yaitu distributive justice, procedural justice, interpersonal justice, dan informational justice (Colquitt \& Greenberg,2003).
JURNAL

MANAJEMEN

INDONESIA

Vol. 17 - No. 2

Agustus 2017 


\section{JURNAL}

MANAJEMEN

INDONESIA

Vol. 17 - No. 2

Agustus 2017
2. Untuk penelitian tentang anteseden organizational citizenship behavior (OCB-I dan OCB-O) selanjutnya, dapat menambahkan tiga dimensi organizational commitment (affective commitment, continuance commitment, normative commitment).

3. Untuk penelitian selanjutnya, dapat menambahkan metode pengumpulan data dengan wawancara dan menggunakan software smart PLS maupun Amos untuk pengujian pengaruh langsung maupun tidak langsung sebagai pengembangan variabel dari penelitian ini.

\section{Daftar Pustaka}

Aamodt, Michael. (2007). Industrial/Organizational Psychology: An Applied Approach (5th edition). Pacific Grove, CA: Wadsworth Publishing.

Allameh, Sayyed Mohsen and Najibeh Abbasi Rostami. (2014). Survey Relationship between Organizational Justice and Organizational Citizenship Behavior. International Journal of Management Academy (IJOMA),2 (3): 1-8. (Diunduh dari http://www.ijoma.org/artic le 12143 188f0432d17f8b24f4c48f12545abbf6.pdf\#page=3\&zoom=120.22,-90,409).

Bies, Robert. J.(2005). Are Procedural Justice and Interactional Justice Conceptually Distinct? In J. Greenberg \& J. Colquitt (Eds.), Handbook of organizational justice (pp. 85-112). Mahwah, NJ: Lawrence Erlbaum Associates.

Budi, Triton Prawira. (2006). SPSS13.0 Terapan; Riset Statistik Parametrik. Yogyakarta: C.V ANDI OFFSET.

Choi, Byoung Kwon, Hyoung Koo Moon, Wook Ko, Kyoung Min Kim. (2014). A CrossSectional Study of The Relationships Between Organizational Justices and OCB: Roles of Organizational Identification and Psychological Contracts. Leadership \& Organization Development Journal,35 (6):530 - 554.

Coetzee, M. (2005). Organizational Justice. University of Pretoria etd. (Diunduh dari http:// upetd.up.ac.za/thesis/available/etd-04132005 130646/unrestricted/04chapter4.pdf).

Colquitt, Jason A. 2012. Organizational Justice, Chapter 16. (Diunduh dari: https://media. terry.uga.edu/socrates/publications/2015/01/Colquitt2012.pdf).

Cropanzano, R., D. E. Bowen, and S. W. Gilliland. (2007).The Management of Organizational Justice. Academy of Management Perspectives,pp.:34-48. (Diunduh dari http://www.wku. edu/cebs/doctorate/documents/readings/cropanzano_etal_2007_organizational_justice. pdf).

DeConnick, James B. (2010). The Effect of Organizational Justice, Perceived Organizational Support, and Perceived Supervisor Support on Marketing Employees'Level of Trust. Journal of Business Research, 63: 1349-1355.

Elamin, Abdallah M., Hayfaa A. Tlaiss. (2015). Exploring The Relationship Between Organizational Citizenship Behavior and Organizational Justice in the Islamic Saudi Arabian context. Employee Relations, 37 (1):2-29.

Fory Armin Naway.(2014). Pengaruh Pengembangan Karir, Persepsi tentang Keadilan Organisasi, dan Kepuasan Kerja terhadap Organizational Citizenship Behavior. Jurnal Manajemen;XVIII (03): 407-425.

Huang, Chun-Chen dan Ching-Sing You. 2011. Three Components of Organizational Commitment on In-role Behaviors and Organizational Citizenship Behaviors. African Journal of Business Management, 5 (28):11335-11344. (Diunduh dari: http://www. academicjournals.org/article/article1380554200_Huang\%20and\%20You.pdf)

Jafari, Parivash and Shabnam Bidarian. (2012). The Relationship Between Organizational Justice and Organizational Citizenship Behavior. Procedia, Social and Behavior Sciences, diunduh dari: http://tarjomefa.com/wp-content/uploads/2016/09/5385-English.pdf

Li, Andrew and Russell Cropanzano. (2009). Do East Asians Respond More/Less Strongly to 
Organizational Justice Than North Americans? A Meta-Analysis. Journal of Management Studies,46 (5): 787-805.

Luthans, Fred. (2006). Perilaku Organisasi, Edisi Sepuluh, Yogyakarta: Penerbit Andi.

Mahmudah Enny Widyaningrum. (2010). Pengaruh Keadilan Organisasi terhadap Kepuasan Kerja, Komitmen dan Organizational Citizenship Behavior Pegawai (Studi Kasus di Rumah Sakit Bersalin Pura Raharja Surabaya). Majalah Ekonomi, Tahun XX (1).

Organ, D.W., Podsakoff, P.M., \& MacKenzie, S.B. (2006).Organizational Citizenship Behavior: Its Nature, Antecedents, and Consequences. Sage, Beverly Hills, CA.

Polat, Soner. (2016). The Relationship Between Organizational Justice Perceptions, Level of School and Administrator Trust, and Organizational Citizenship Behaviors of Secondary School Teacher Turkey; diunduh dari http://files.eric.ed.gov/fulltext/ED507710.pdf).

Ratnawati, dan Khairul Amri. (2013). Pengaruh Keadilan Organisasional, Kepercayaan pada Atasan terhadap Perilaku Kewargaan Organisasi (Organizational Citizenship Behaviors). Jurnal Ekonomu Manajemen dan Bisnis; 1 (1): 56-73.

Robbins, Stephen P, Timothy A. Judge (2015). Perilaku Organisasi, PT. Salemba Empat, Jakarta.

Sekaran, Uma. (2003). Metodologi Penelitian Untuk Bisnis. Jakarta: Salemba Empat

Simpson, P.A., and Kaminski, M. (2007), Gender, Organizational Justice Perceptions, and Union Organizing. Employee Responsibilities and Rights Journal,19 (1): 57-72.

Sugiyono.2011. Metode Penelitian Pedidikan Pendekatan Kuantitatif, Kualitatif, dan R\&D. Bandung: ALFABETA.

Veronika Agustini S., Sri Rustiyaningsih, dan Dyah Kurniawati. (2015). Kepemimpinan yang Melayani dan Pengaruhnya terhadap Kinerja Guru SMAdan SMK Swasta di Kota dan Kabupaten Madiun dengan Employee Engagement dan Perilaku Ekstra-Peran sebagai Pemediasi. Simposium Nasional "The 8th and Doctoral Colloquium”, Fakultas Bisnis dan Pascasarjana Unika Widya Mandala Surabaya, 29 September 2015.
JURNAL

MANAJEMEN

INDONESIA

Vol. 17 - No. 2

Agustus 2017 